\title{
Review of Fashion, Technology and Health: Future Directions for the Apparel Industry
}

\author{
Rachel J Eike* and Sonia Bakhshian \\ Apparel Merchandising and Design, Iowa State University, USA \\ *Corresponding author: Rachel J Eike, Iowa State University, 1068 Le Baron Hall, 626 Morrill Rd, Ames, Iowa 50011, USA
}

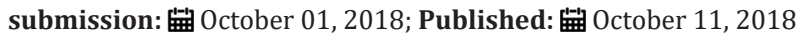

\begin{abstract}
This review briefly analyzes fashion, technology, and health-related observations in industries to make suggestions for the future direction of growth for apparel and product development. This article highlights technology-embedded apparel and textile products currently presented in the market or made known via web promotion or conference exhibition. Many of these textile products are primarily associated with health care and fitness-related intentions - showing support and direction of health and technology for a future scope in fashion and apparel industries. The objective of this review was to identify challenges associated with 'smart' textile production, reference examples of technology integration in textile-based wearables and make recommendations for the design and development direction of future apparel products.
\end{abstract}

Keywords: Fashion; Health; Technology; Apparel; Smart textiles

\section{Introduction}

Wearables are devices worn on the body that have conductivity capabilities, advanced circuitry, and communication capability. The market for wearable technology has been slowly growing since the 1970s and has dramatically increased in recent years from the popularity of fitness trackers and smartwatches. According to the report published by Scalar Market Research [1], the wearable technology market was valued at $\$ 29.92$ billion dollars in 2016 and is predicted to more than double to a value of $\$ 71.23$ billion by 2021 One category of the wearables market includes textiles with conductive capabilities (referred to as electronic textiles, e-textiles, smart textiles, smart clothing, or functional fabrics). Although the wearables market is now a multi-billion dollar industry, 'smart' garments represents less than $1 \%$ of the global wearables market [2]. This 'smart' clothing sector of the wearables market is estimated to be a \$50-billion industry by 2025 and it is predicted that most of the growth will be attributed to innovative product development $[3,4]$. Smart textiles are evolving to collect bodily data and communicate it directly from the integrated or embedded tech of the textile/fabric to a device for analysis and monitoring (self or professional). This emerging field of smart textile wearables will have a dramatic impact on human-computer interaction, specifically in regard to health and safety monitoring. This review article recaps the evolutions of technology and apparel/textiles, identifies some challenges the industry faces with technology and textile integration, and outlines some products and institutions making headway on this future direction for fashion: health and technology.

\section{Review}

\section{Evolution of technology and apparel}

Emerging technology is changing the future direction of the fashion industry to take on a transdisciplinary approach that further involves designers, merchandisers, product developers, material science professionals, engineers, plus others, to change the way consumers wear and interact with their clothing and other 'soft good' products. Beyond apparel applications involving the treading of connective wires through garment interiors and plugging into a hard connector, conductive inks and conductive thread (via embroidery stitching) are some examples of recent innovations in apparel and textiles regarding the applied approach for manufacturing wearable technologies. Conductive ink that is printed and then heat-set onto a textile substrate has been developed so that it can be stretched more than three times its original shape while keeping conductivity [5]. Du [6] has also developed a series of functional, stretchable electronic ink materials for smart clothing and other wearable electronic application that is durable and launderable (withstanding up to 100 cycles). This applied printed technology allows everyday clothing to be transformed into a smart garment that features flexible circuitry and sensors. This technology in clothing has seen growth in the performance sportswear arena as it can capture performance information via "biosensors" that monitors electrocardiography heart rate, electromyography muscle activity, respiratory rate, body temperature, and capacitive touch sensors 
that can detect fluid levels (Butler Technologies, Inc., personal communication via IPC conference panel, September 13, 2018).

Embroidery of conductive threads onto a textile substrate has also shown to be a progressive approach to applying technology into smart soft goods, taking on the form of a textile antenna. Textile antennas are a key component for wireless body area network (WBAN) applications so as to guarantee wear-ability (user comfort) and system reliability [7]. Embroidery is viewed by some as an approach that has mass production capabilities as embroidery machines allow for repeatability and customization in terms of thread selection and placement (location on garment, shape of stitch, and stitch design) $[7,8]$.

Conductive yarns are an emerging area for fabrication of smart clothing which embeds or integrates technology into the textile of apparel or other textile-based products. Conductive yarns can be integrated into textiles during the yarn development process (twisting plies of conductive and non-conductive yarns) to create a fabric that can carry communicative current along the length or width of the fabric piece - woven or knitted - while still performing as a comfortable garment worn daily by consumers. An example of this type of yarn development for fabrication may be a Nickel-Copper yarn plied with a polyester or nylon yarn and twisted together - resulting in conductive properties from the nickel-copper and strength and comfort from the polyester component. Conductive coatings on textiles have also been studied and show potential for both garment and antenna applications [9]. The development and evolution of these technology applications into textiles and apparel show encouraging advancements for the monitoring of health-related outcomes, including safety, performance, and rehabilitation, to name a few.

Industry challenges for embedding tech: While substantial progress has been made in the apparel sector involving the integration of technology, the industry faces challenges. Despite the rapid growth of attachable wearable technology (smartwatches, fitness trackers, snap-on pods), the lack of adoption in the smart clothing category is due to many factors, some of which include: technical challenges with sensor size, conductivity accuracy, and performance with garment style as well as textile formation (weaving/ knitting, non-woven, direct printing) and manipulation (embroidery, lamination, layering, coating, direct printing) (Stephanie Rodgers of Apex Mills and Diana Wyman, Technical Director of AATCC, personal communication via IPC conference, September 13, 2018). When looking at woven e-textiles, while the textile may be more stable (i.e., easier to put conducting component in filling yarn direction) this approach will require an engineered fabrication design approach and the end product is difficult to connect with sensors, which need contact with skin to collect bodily information. While knitted e-textiles would allow for a more form-fitting finished product that could potentially rest snuggly against the skin for bodily sensor data monitoring, the greatest challenge rests with getting production equipment to operate slow enough so that the conductive yarns do not break [10]. Currently, mass production of knitted e-textiles has been unsuccessful at this point (Stephanie Rodgers,
Director of Product Research and Development at Apex Mills and Co-founder of Textile Foundry, personal communication via IPC conference, September 13, 2018). Xu [11] identified e-textile deformation and conductivity change under a variety of wear conditions, including abrasion, laundering, perspiration, and strain. These results show great challenges in the physical wearablity and care (launderability) of e-textiles currently available on the market. In addition, as the development of new e-textiles come into formation this requires the development of new testing standards and protocols to be developed. Finally, as these tech-integrated textiles are evolved into products, there will be a need to expand technical support for these products, which might include app updates and computer/store in cloud requirements (Dan Ledger, Path Collaborative, personal communication via IPC conference, September 13, 2018).

\section{Design and health}

When entering any fashion retailer, it is easy to see how products offered have expanded to a plethora of specialized items that fit the consumers' needs and style desires. Looking specifically at the athletic wear department, what was once a department organized by sport for performance (running, tennis, basketball, soccer, etc.) now has defined areas that include more casual wear (ac-leisure) and more specialized equipment: cross-training shoes, yoga mat gloves, and stationary cycling footwear. This growth in specialized products that fall within the greater 'fashion' umbrella, communicate to design professionals that consumers desire to have customized products that fit their specific need(s) and personal aesthetic. This desire for product variety and customization can easily be translated into the arena of healthcare. Designing for healthcare may be viewed as functional garments or products developed to maintain and enhance physical health. Scholars and industry professionals are finding opportunities to improve physical health of individuals through the development of intervention strategies via functional garments that now include the integration of technology. The table below outlines a sampling of these tech-integrated health-focused wearable products (Table 1, [12-18]).

\section{Discussion and Future Directions}

In this short review, the evolution of technology in apparel/ textiles was discussed and challenges for the embedding of tech into textiles for mass manufacturing and adoption were outlined. Additionally, the progression of consumer product offerings pointing to the growth of the health market, including wellbeing, safety, and physical movement and rehabilitation was briefly discussed and identified in table format. Key characteristics that are linked to challenges in product development and production may be labeled into three categories: 1) embedded or applied tech, 2) fabrication technique: woven, knitted, printed, or embroidered technology, and 3) hard or soft component. The component category involving hard or soft materials is observed to be the biggest challenge as many of the samples identified in this review had hard material circuitry or connectors, which may lead to comfort, wear, and launderability issues for mass adoption. Seamless integration of flexible circuitry, sensors, antennas, and power sources are key components to the reliable and successful operation of any smart textile or smart gar- 
ment. The complexity of designing, creating, manufacturing, marketing, and retailing 'smart' products requires collaborative networks. Combining research and creativity with realistic production methods requires dynamic collaboration from transdisciplinary ar- eas - bringing together disciplines of biotechnology, medicine, material sciences, electronics, computer science, textiles, and product and fashion design are essential for the successful design, production, and true functionality of the future of the wearables industry.

Table 1: Sampling of health-focused technology integrated textile products.

\begin{tabular}{|c|c|c|c|c|c|c|}
\hline $\begin{array}{l}\text { Product } \\
\text { Name }\end{array}$ & $\begin{array}{c}\text { Institution \& } \\
\text { Source }\end{array}$ & Market Poten- & \multicolumn{3}{|c|}{ Tech Characteristics } & Product Image \\
\hline & & & $\begin{array}{l}\text { Applied or } \\
\text { Embedded }\end{array}$ & $\begin{array}{l}\text { Fabrica- } \\
\text { tion of } \\
\text { tech }\end{array}$ & $\begin{array}{l}\text { Hard or Soft } \\
\text { Components }\end{array}$ & \\
\hline SKIIN & Myant [12] & Mass market & Embedded & Knit & Hard & \\
\hline $\begin{array}{l}\text { Team USA } \\
\text { Heated } \\
\text { Jacket }\end{array}$ & $\begin{array}{c}\text { Polo Ralph } \\
\text { Lauren and } \\
\text { Butler Technol- } \\
\text { ogies, Inc. [13] }\end{array}$ & Mass market & Applied & Printed & Soft & \\
\hline $\begin{array}{l}\text { Levi's® } \\
\text { Commuter } \\
\text { X Jacquard } \\
\text { By Google }\end{array}$ & Levi's@ [14] & Mass market & Embedded & Woven & Hard & \\
\hline $\begin{array}{c}\text { Smart } \\
\text { Fabric } \\
\text { Bellyband }\end{array}$ & $\begin{array}{l}\text { Drexel Univer- } \\
\text { sity: Center } \\
\text { for Functional } \\
\text { Fabrics [15] }\end{array}$ & $\begin{array}{l}\text { Specialized } \\
\text { market }\end{array}$ & Embedded & Knit & Soft & \\
\hline Life vest- & Zoll [16] & $\begin{array}{l}\text { Specialized } \\
\text { market }\end{array}$ & Applied & $\begin{array}{c}\text { Embroi- } \\
\text { dery \& } \\
\text { Print }\end{array}$ & Hard & \\
\hline $\begin{array}{c}\text { Textile } \\
\text { Electrode } \\
\text { Headband }\end{array}$ & Myant [17] & $\begin{array}{c}\text { Individual } \\
\text { customization - } \\
\text { Couture }\end{array}$ & Embedded & Knit & Hard & \\
\hline
\end{tabular}




\begin{tabular}{|c|c|c|c|c|c|c|}
\hline $\begin{array}{c}\text { Movement } \\
\text { for Paralysis }\end{array}$ & Myant [18] & $\begin{array}{c}\text { Individual } \\
\text { customization - } \\
\text { Couture }\end{array}$ & Embedded & Knit & Hard & (n) \\
\hline
\end{tabular}

Note: Hard Components refers to hard wired connections to power or communicate bodily data to device for analysis. Soft Components refers to technology that does not include the use of hard wires for power, data collection, or communication.

While the products in this review may be seen as a limitation in this article, the items outlined provide an overview of potential market categories in the fashion sector for growth and development to integrate technology. For future research and projected direction in the fashion industry it is recommended to increase focus on three main areas: 1) designing for all (e.g., designs that promote inclusivity, comfort, \& performance), 2) heath \& wellness monitoring (e.g., merging of technology into everyday wear, low profile, un-noticeable, integrated/embedded tech), and 3) user-centered approaches (e.g., developing products \& experiences unique to the individual, custom medical items for specific treatments and checkups such as labor and delivery, breast cancer, and or medical rehabilitation). It is suggested that research and development teams aim to develop wearable products that hide this advanced functionality. This may involve the development of components so small they can fit anywhere and run on thermal energy generated by the body. Another suggestion is to design wearable products that affect bodily functions and not just measure them. This may involve products that directly optimize aspects of our physiology.

There is also great potential for curriculum development in the academic sector, as students may struggle to see and understand the transdisciplinary connection between design, technology, and health. It is recommended that fashion and product development programs reexamine curriculum to meet specific health-focused areas that integrate technology in the near future.

\section{References}

1. Wearable Technology Market (2016) Scalar market research.

2. Woods V, Van MR (2016) Worldwide wearable devices sales to grow.

3. http://go.affoa.org/category/news/

4. Clemson, Milliken, Inman Mills Team on Textile Project (2016) Charleston regional business journal (April 1), Charleston, South Carolina, USA.

5. Matsuhisa N (2015) Printable elastic conductors with a high conductivity for electronic textile applications. Nat Commun 6: 1-11.

6. Du P (2017) Making smart clothing easier to design, manufacture, wash and wear. Product data sheets.

7. Gil I, Fernández-García R, Tornero J (2018) Embroidery manufacturing techniques for textile dipole antenna applied to wireless body area network. Textile Resarch Journal.

8. Wang Z, Zhang L, Volakis J (2013) Textile antennas for wearable radio frequency applications. Textiles and Light Industrial Science and Technology 2(3): 105-112.

9. Xu B, Eike RJ, Cliett A, Cloud RM, Li Y (2018) A short review of textile applications in antenna design. Trends in Textile Engineering \& Fashion Technology 1(5).

10. Dion G (2013) Garment device: Challenges to fabrication of wearable technology in Proceedings of the $8^{\text {th }}$ international conference on body area networks.

11. Xu B, Eike RJ, Cliett A, Ni L, Cloud RM (2018) Durability testing of electronic textile surface resistivity and textile antenna performance. Textile Research Journal.

12. Myant (2018) SKIIN Underwear. Myant Solutions.

13. BTI (2018) Printed heaters: Made in the USA for the USA. Butler Technologies, Inc, India.

14. Google (2018) Jacquard enabled, you empowered.

15. Dion G (2014) Smart fabric bellyband. Integrated Design Research \& Engineering for Advanced Manufacturing (IDREAM) Research Projects.

16. Zoll (2017) How does the life-vest wearable defibrillator work? Zoll medical corporation, USA.

17. Myant (2018) Communication by blinking. CBS News, New York, USA.

18. Myant (2018) Garment-based neuro-orthosis. Sam Schmidt's Story.

Creative Commons Attribution 4.0 International License

For possible submissions Click Here Submit Article

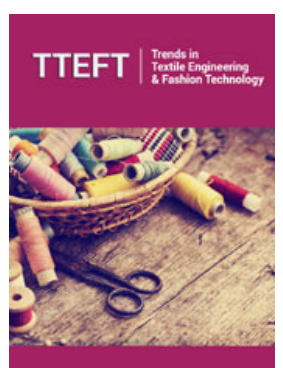

Trends in Textile Engineering \& Fashion Technology

\section{Benefits of Publishing with us}

- High-level peer review and editorial services

- Freely accessible online immediately upon publication

- Authors retain the copyright to their work

- Licensing it under a Creative Commons license

- Visibility through different online platforms 